\title{
Psychomotor Activities for the Integral Development of Children Who Receive the "Educate Your Child" Program in Non-Institutional Ways
}

\author{
Irma de las Mercedes Muñoz Aguilar*, Rafael Lázaro Tamarit Medrano and Olga Lidia Pernas de Armas \\ Department of Physical Culture, University of Camagüey, Cuba
}

*Corresponding author: Irma de las Mercedes Muñoz Aguilar, Department of Physical Culture, University of Camagüey, Cuba

\begin{abstract}
This article reports a study developed with a population of 20 graduated teachers of Preschool Education, who attend the non-institutional ways, through structured observation, it was found that the cognitive, affective and emotional dimension is given greater treatment. of this program, the motor being the least treated, so that activities and games are designed taking into account the bio-psychosocial characteristics of children from four to six years old, the diagnosis made to the teachers about the execution of this program, as well as the potential that psychomotor skills provide to be used for the purpose that is proposed.
\end{abstract}

Keywords: Preschool age; "Educate your child” program; Psychomotricity; Cognitive; Affective; Social and motor dimensions

\section{Introduction}

Children of pre-school age in Cuba, who do not attend day care centers, are cared for in the program "Educate your child", which is a non-institutionalized educational modality, which deals with four dimensions, the cognitive, the affective, social and motor in each of which activities are carried out to stimulate the integral development of children, this program is executed by a multidisciplinary group, in conjunction with the family in the main role and participation of the community. In the case of the motor dimension, it is designed according to the principles that govern preschool physical education, and the theoretical foundations of psychomotricity [1-3]. Psychomotricity can be understood globally, since it perceives the interactions between the motor and the psychism; as between the individual and the outside world and allows the person to know in a concrete way his being and his immediate environment to act in an adapted way [4]. On the other hand, the psychomotricity is basic in the development of the boy and the girl since it is a global education, that associates the intellectual, affective, social, motor and psychomotor potentials of the boy and the girl, gives him a great security, a balance and allows its development by correctly organizing its relations with the different media, in which they are called to evolve [5]. Therefore, in the motor dimension of the "Educate your child" program, activities and games should be included that allow, in addition to developing basic motor skills, others that comprehensively address the intellectual, affective and social potentials, in accordance with the principles of cultural historical approach of the Cuban school $[6,7]$.

\section{Materials and Methods}

In order to carry out this work, we studied the population of 20 graduated teachers of Preschool Education, who attend the non-institutional routes in the popular council Vista Hermosa de Camagüey, which represent $100 \%$, through structured observation, at 13 programmed activities, it was possible to confirm that the cognitive dimension is given greater treatment, followed by the affective and social dimension, with the motor being the one that reaches the last place in all cases [8].

\section{Results and Discussion}

Based on the criterion that psychomotricity has a global character and develops intellectual, affective, social, motor and psychomotor potentials of boys and girls, activities and games for the development of visual, auditory perception were included in the motor dimension of this program. and tactile, for the formation of spatiality; as well as time-rhythm; For corporal expression, free dances, soft dances, dramatized corporal mimicry and for verbal expression were used, as well as activities such as telling stories, 
inventing stories, continuing incomplete sentences, songs, poems and dramatizations. Specifically, for motor skills, activities such as manipulating objects with one hand, foot, looking with one eye, writing in the air, imitating peer movements, moving with different traces, symmetrical positions were carried out for the body outline and laterality. and asymmetric, awareness of the parts of the body, keep objects in balance, stay on one foot, climb surfaces with little support base, adopt different body postures, as well as activities that have to vary the center of gravity. As the game has great educational and recreational importance, and at the same time produces pleasure, [9] motor games were included with or without implements specifically for the development of basic motor skills according to age, cognitive games such as: riddles, imitations, songs , Word games; with materials: puzzles, chess, checkers, crossword puzzles and social games in which role plays were developed: dad, mom, police, teacher, driver, school cleaning, discipline, personal and house hygiene.

Ecological games were also included, with tours formed by different materials of nature such as tree trunks, leaves of different types, sizes, textures and colors, models of animals and fruits, which had to identify them and mention their characteristics through sensory systems of vision and touch. Considering that the preschool age is the foundation for the healthy and harmonious growth of the boy and girl [10], activities and games for the education of breathing were included; such as blowing a partner, blowing paper balls, ping pong balls, inflating imaginary balloons and real balloons; as well as for the formation of the correct posture [11]; like walking imitated different animals, carrying books on the head, among others.

\section{Conclusion}

The treatment of psychomotricity in its current conceptualization is of paramount importance in the context of preschool physical education since it induces a global education based on the exploration of its body and the relationship with the environment that surrounds it. all motor, intellectual, affective, and social potentialities in terms of preparing children for future life. The observation made it possible to confirm that the cognitive dimension is the one that reaches the highest values, followed by the affective and the social, being the motor that obtains the last place in the three moments of the observed activities. The design of the psychomotor activities for the joint development of the dimensions of the "Educate your child" program in the non-institutional routes for boys and girls from four to six years old, was made taking into account the biopsychosocial characteristics of children from four to six years old, the diagnosis made to the teachers about the execution of this program, as well as the potential that psychomotor skills provide to be used for the purpose that is proposed, on the other hand in its context contains the elements methodologies that respond to the algorithm of the Cuban school so it has a systemic approach.

\section{References}

1. Ministry of Education (1998) Program for the family aimed at the integral development of the child, "Educate Your Child". Editorial People and Education, Havana.

2. Bequer G (2004) Preschool Physical Education: Notes. Editorial INDER, Havana.

3. Escribá A (1999) Psychomotricity: Theoretical foundations applicable to practice: Editorial Gymnos, Madrid, Spain.

4. Mendiara J, Gil P (2003) Psychomotor: Evolution, currents and current trends. Wanceulen, Seville, Spain.

5. Vayer P, Escribá A (1999) Psychotricity: Theoretical foundations applicable to practice. Gymnos, Madrid, Spain, p.189.

6. Collective of authors (1983-1993) Study project on the inclusion of nonformal pathways within the preschool education program. Editorial Central Institute of Pedagogical Sciences, Havana, p.134.

7. Morenza L, Terré O (1998) Historical-cultural school. Education Magazine, Havana p. 93.

8. Pernas OL (2010) Plan of psychomotor activities for the joint development of the dimensions of the "Educate your child" program in non-institutional ways. Havana.

9. Watson H (2008) Theory and practice of games. Editorial Sports. Havana.

10. Rodríguez AC (2009) Prevention and Preschool Education. Editorial People and Education, Havana.

11. Muñoz I, Pérez N (2003) Study of the most frequent orthopedic deformities in children attending the Clara Zetquin Children's Circle of the province of Camagüey. Symposium of Therapeutic Physical Activity and Special Education, Havana.

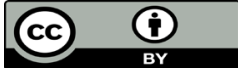

This work is licensed under Creative Commons Attribution 4.0 License

To Submit Your Article Click Here:

Submit Article

\section{OJNBD}

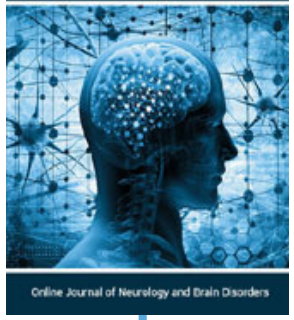

\section{Online Journal of Neurology} and Brain Disorders

\section{Assets of Publishing with us}

- Global archiving of articles

- Immediate, unrestricted online access

- Rigorous Peer Review Process

- Authors Retain Copyrights

- Unique DOI for all articles 